\title{
PRELIMINARY SHEAR-WAVE SPLITTING RESULTS IN THE BROADER AIGION AREA (GREECE) DURING 2013
}

\author{
Kaviris G. ${ }^{1}$, Spingos I. ${ }^{1}$, Kapetanidis V. ${ }^{1}$ and Papadimitriou P. ${ }^{1}$ \\ ${ }^{l}$ National and Kapodistrian University of Athens, Department of Geology and Geoenvironment, \\ 15784,Zographou, Athens, Greece,gkaviris@geol.uoa.gr,ispigos@gmail.com, \\ vkapetan@geol.uoa.gr,ppapadim@geol.uoa.gr
}

\begin{abstract}
An anisotropic upper crust has been revealed in the W. Gulf of Corinth with potentially changing properties. During 2013, a unique opportunity to conduct a shear-wave analysis was presented, as a combination of the significantly increased seismicity in the area, including a seismic swarm between May and August, and the existence of local seismological networks. The Hellenic Unified Seismological Network (HUSN) and the Corinth Rift Laboratory Network (CRLN) provided invaluable data during the unrest period. While shear-waves travel through an anisotropic medium, the splitting phenomenon takes place and, as a result, their propagation is characterized by two discernible components: the fast $\left(S_{\text {fast }}\right)$ and the slow $\left(S_{\text {slow }}\right)$ one, which arrives to the station in a subsequent temporal point. Modern advances in seismology and geophysics have rendered shear-wave splitting a valuable tool in determining properties of the anisotropic propagation media. One of the predominant causes of this phenomenon is the existence of microcracks throughout the upper crust. The current study presents results for 8 stations from 535 analyzed events that are in agreement with the anisotropy models of EDA and APE. Keywords: seismic anisotropy, Gulf of Corinth, seismic swarm.
\end{abstract}

\section{Пєрí $\eta \psi \eta$}

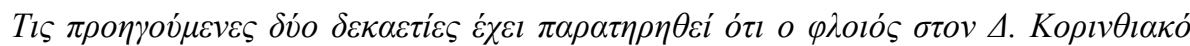

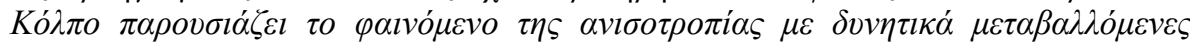

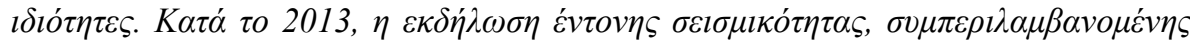

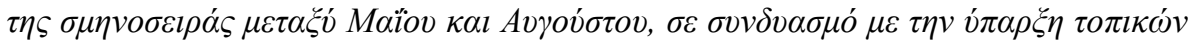

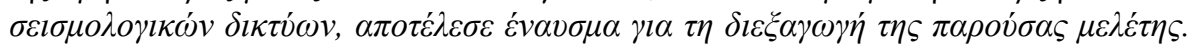

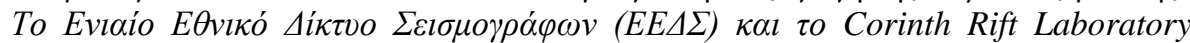

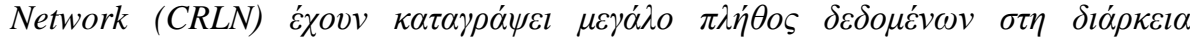

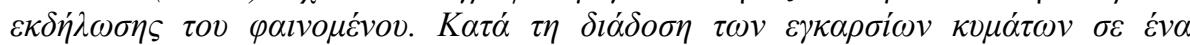

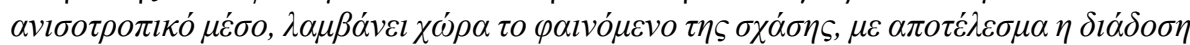

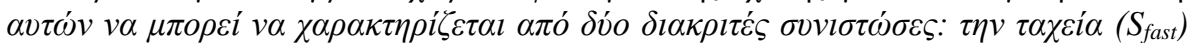

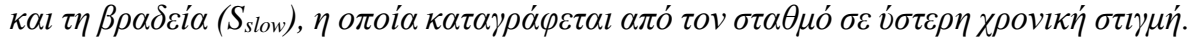

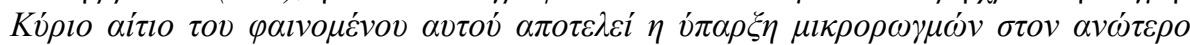

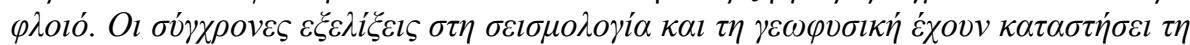

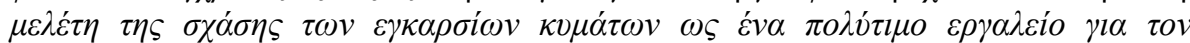

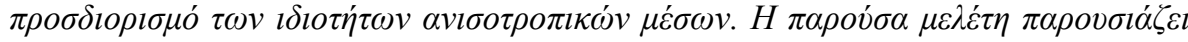

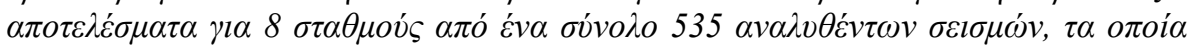

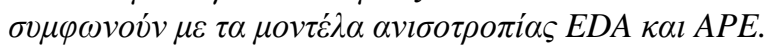

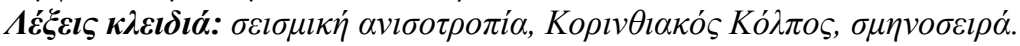




\section{Introduction}

The Gulf of Corinth $(\mathrm{GoC})$, located in Central Greece, is a key area for seismological studies in Europe, due to the high local seismicity (Makropoulos and Burton, 1984; Papadimitriou et al., 2010) and the existence of dense seismological networks, namely the regional Hellenic Unified Seismological Network (HUSN), composed of stations operated by the Seismological Laboratories of the National and Kapodistrian University of Athens and the University of Patras, the Department of Geophysics of the Aristotle University of Thessaloniki and the Institute of Geodynamics of the National Observatory of Athens, as well as the local Corinth Rift Laboratory Network (CRLN) with stations in the broader Aigion area (Lyon-Caen et al., 2004). These two networks are complementary to each other and enable the location of hypocentres with small uncertainties.

The extended study of the GoC by multiple researchers in the past has provided valuable insight about the tectonic processes that dominate the region. The gulf is characterized as a complex asymmetric half-graben (Armijo et al., 1996). The normal fault systems in the area strike approximately E - W, causing the uplift of the southern shore of the gulf and the extension in a general NNE - SSW direction (Fig. 1), while dipping northward (Hatzfeld et al., 2000). However, there are south dipping antithetic faults of lesser significance to the tectonic evolution of the area (Bell et al., 2009), located at the northern part of the gulf and offshore. A detachment zone with normal faulting characteristics and a $15^{\circ}$ northward dip has been observed beneath the gulf at approximately $10 \mathrm{~km}$ depth (Rigo et al., 1996).

Seismicity in the study area (Fig. 1) reveals a plethora of strong earthquakes since the preinstrumental era (Galanopoulos, 1936, 1960; Papazachos and Papazachou, 2003; Kouskouna and Makropoulos, 2004). This trend that also continued in the modern period of seismology, since 1900, has led to the occurrence of several large earthquakes $\left(\mathrm{M}_{\mathrm{w}} \geq 6.0\right.$, Makropoulos et al., 2012), such as the Galaxidi earthquake (Hatzfeld et al., 1996). One of the most well-known seismic events of the recent decades is the 15 June $1995\left(M_{s}=6.2\right)$ Aigion earthquake (Bernard et al., 1997a). Since the occurrence of the Aigion event, the seismic energy in the Western GoC (WGoC) is mainly expressed by the generation of seismic swarms and not specific strong events (Lyon-Caen et al., 2004; Duverger et al., 2015; Kapetanidis et al., 2015). The two strongest events of this period were located at the northern part of the GoC, close to Efpalio city, in 2010 , both with a magnitude of $\mathrm{M}_{\mathrm{w}}=5.1$ (Kapetanidis and Papadimitriou, 2011; Ganas et al., 2013).

Seismic anisotropy is the variation of seismic velocity in different propagation directions. When shearwaves enter an anisotropic medium, they split into two distinct components, presenting discernible seismic velocities. The phenomenon has been attributed to several causes, such as the lattice preferred orientation of minerals in sedimentary rocks (Valcke et al., 2006) or in accordance with the orientation of sedimentary grains (Crampin et al., 1984). In settings dominated by tectonic processes, it can be interpreted by the Extensive Dilatancy Anisotropy (EDA) model, according to which fluid-saturated microcracks, oriented parallel to the maximum horizontal compressive stress component, exist in the rockmass and control the anisotropy direction (Crampin, 1978). The evolution of EDA is the Anisotropic Poro-Elasticity (APE) model, which incorporates pore fluid pressure in understanding the mechanisms that govern seismic anisotropy in the upper crust (Crampin and Zatsepin, 1997). Microcrack-controlled anisotropy has been observed in both volcanic and tectonic environments, such as Iceland (Crampin et al., 1999), Greece (Papadimitriou et al., 1999, 2010; Kaviris et al., 2008, 2014, 2015), Italy (Bianco et al., 2006) and U.S.A. (Liu et al., 2008). 
In the framework of the current study, an anisotropy analysis was conducted in the WGoC during 2013, including the period of the Helike seismic swarm (Chouliaras et al., 2015; Kapetanidis et al., 2015). The data were recorded by stations belonging to both the HUSN and the CRLN. The manual processing of waveforms utilized the polarigram (Bernard and Zollo, 1989) and hodogram methods, leading to the measurement of two shear-wave splitting parameters: the polarization direction of the shear-wave component with the higher velocity $\left(S_{\text {fast }}\right)$ and the time-delay between the arrival of the $\mathrm{S}_{\text {fast }}$ and the slow component $\left(\mathrm{S}_{\text {slow }}\right)$.

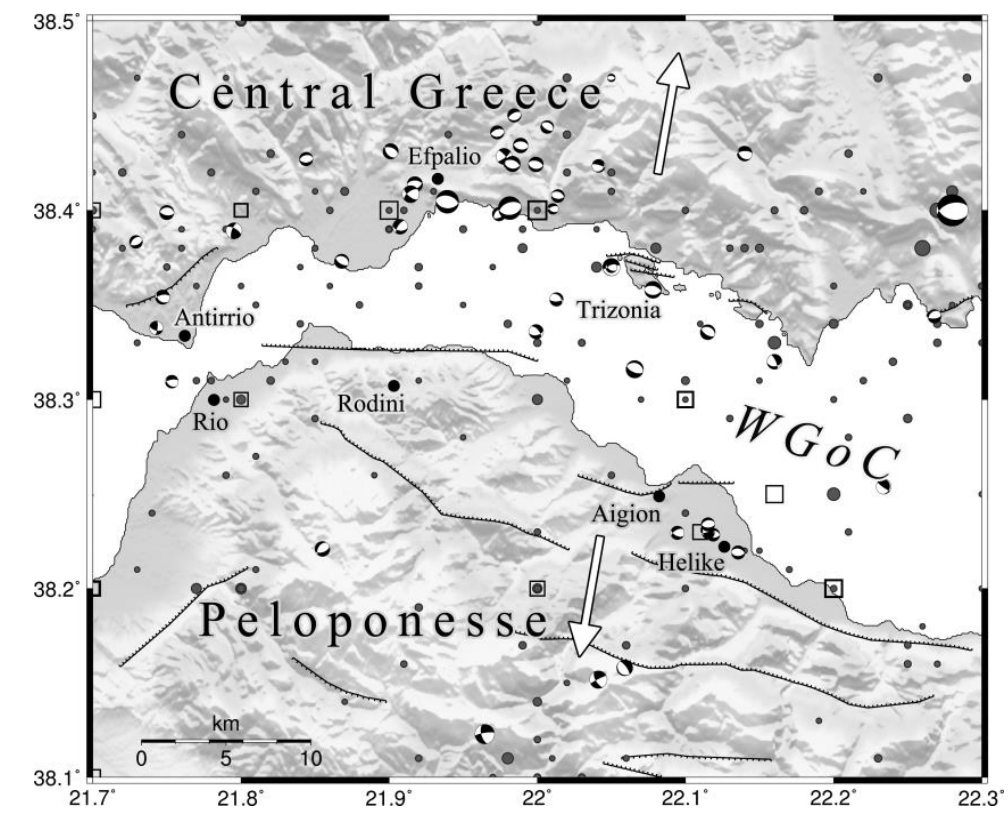

Figure 1 - Seismotectonic Map of the WGoC. Focal mechanisms are published in the webpage of the Department of Geophysics of the University of Athens. Squares represent epicentres of

historical events (Papazachos and Papazachou, 2003), whereas circles correspond to earthquakes that occurred since 1900 (Makropoulos et al., 2012). The arrows present the direction of extension of the gulf. Fault traces have been digitized in the Seismological Laboratory of the University of Athens (Karakonstantis and Papadimitriou, 2010).

\section{Data and Method}

The local seismological stations of HUSN and CRLN enabled the recording of a great amount of data and the highly precise location of the selected events. A total of 535 events that occurred during 2013 in the W. GoC were utilized, having focal depths between $6 \mathrm{~km}$ and $12 \mathrm{~km}$. Location errors were very satisfactory, having mean values equal to $0.6 \mathrm{~km}$ for the horizontal (ERH) and $0.9 \mathrm{~km}$ for the vertical (ERZ) one, while mean RMS was equal to $0.13 \mathrm{sec}$. Hypocenters of events belonging to the May - August seismic swarm were adopted by Kapetanidis et al. (2015). The earthquakes selected for the study meet certain strict criteria. Each event is located within the shear-wave window with an angle of incidence equal to or less than $45^{\circ}$, to avoid interaction with the free surface (Booth and Crampin, 1985). Furthermore, the shear-wave amplitude of the vertical component is smaller than that of the horizontal ones, preventing converted or scattered phases. The utilized waveforms presented a high Signal-to-Noise Ratio (SNR) in order to exhibit clear and impulsive phases, minimizing the possibility of false S-wave arrival identification (Kaviris, 2003).

The current study was conducted using visual techniques to provide more accurate and verified results. Polarigrams and hodograms were applied to estimate the shear-wave splitting parameters. Events that exhibit highly elliptic polarization are rejected (Papadimitriou et al., 1999; Kaviris et al., 2010). 

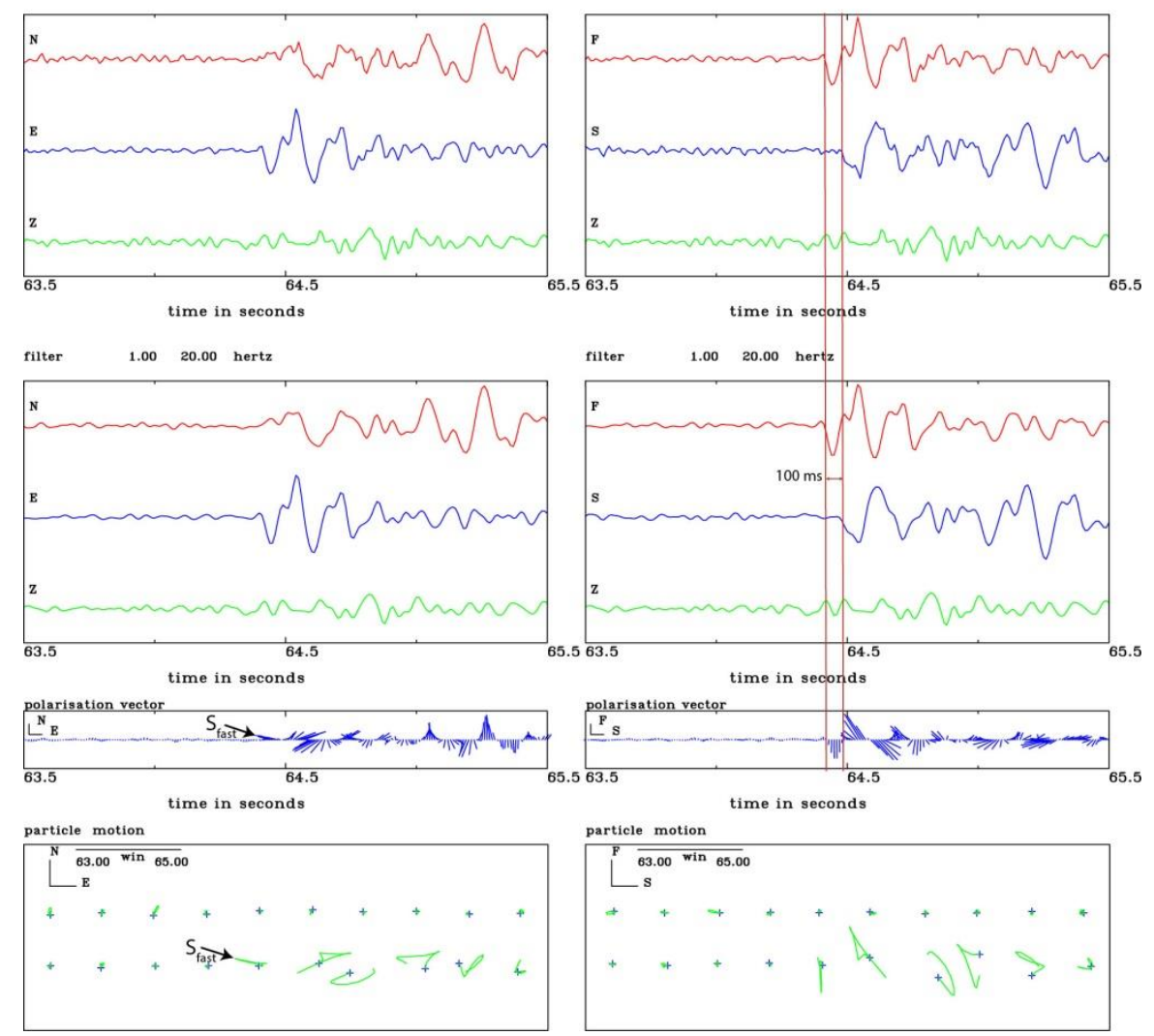

Figure 2 - (a) Original traces (top) of an earthquake recorded at KALE station, filtered traces (middle up), polarigram (middle down) and hodogram (bottom) in the N-E plane where the polarization direction of the fast shear-wave is measured, as indicated by the black arrow. (b) Traces rotated to the fast and slow directions, filtered waveforms of the rotated traces, polarization vector and hodogram in the fast/slow plane where the time-delay is measured (indicated by the two red vertical lines).

In Fig. 2a, an example of an event that meets the selection criteria and was used in the anisotropy study is presented. A band-pass Butterworth filter in the frequency range of $1 \mathrm{~Hz}-20 \mathrm{~Hz}$ was applied on the original waveform. The event occurred on 4/8/2013 18:04:48 GMT, with an azimuth equal to $292^{\circ}$ and an angle of incidence equal to $13^{\circ}$, within the shear-wave window. The selected waveforms were recorded by KALE station, located in the town of Kallithea, near the northern coast of the GoC. This station belongs to the Seismological Laboratory of the National and Kapodistrian University of Athens, as a part of HUSN, and is characterized by small epicentral distances for events located at the northern coasts of the GoC and offshore. Both the polarigram and hodogram of the N-E plane are presented, where the shear-wave splitting phenomenon can be clearly observed, as evidenced by the different $\mathrm{S}$-wave arrival times in the two horizontal components. The fast shearwave polarization direction, measured clockwise from the north, is found equal to $\mathrm{N} 105^{\circ} \mathrm{E}$ and is also confirmed by the hodogram, where the particle motion in the above direction is evident. Hodograms can be utilized for the accurate measurement of the polarization direction when the fast axis coincides with the polarigram's horizontal axis (i.e. the polarization direction is $\sim \mathrm{N} 90^{\circ} \mathrm{E}$ ).

Then, the seismograms are rotated to the fast and slow direction. The obtained waveforms and particle motion diagrams are presented in Fig. 2b. As observed, the polarization vector of the fast 
component is perpendicular to the slow component axis and thus confirms the measurement performed during the previous step. In order to estimate the time delay, the fast component waveform is temporally moved towards the slow one, until the arrivals of the shear-wave in the two components coincide. In this case, the time delay is equal to $100 \mathrm{~ms}$ and represents the magnitude of anisotropy.

\section{Results}

The seismological network in WGoC is one of the densest in Greece, the other being in Santorini (Kaviris et al., 2015; Papadimitriou et al., 2015). Nevertheless, certain stations could not be used for the present anisotropy analysis. For instance, certain stations of the CRLN, while located near the seismic swarm's epicentres, are installed in boreholes and, thus, the orientation of the seismometers is unknown. Time periods with no or very few events, in several stations, are either due to operational problems or lack of seismicity within the shear-wave window. This is observed, for example, in the LAKA station, where there is a significant amount of anisotropy measurements from May until early November, including the Helike seismic swarm, while in the first four months of 2013 the number of results is limited to 3. Another significant problem that led to a broad exclusion of waveforms from the analysis was the low SNR, which rendered the arrival of shearwaves ambiguous.

Concerning the spatial distribution of the analyzed events, the degree of azimuthal coverage for each station, as presented by the equal-area projections of Fig. 3, is predominantly controlled by the location of seismicity and, most importantly, by the existence of various seismic clusters. Stations that provide results in almost all azimuths are EFP and PSAR. Northern stations (i.e. KALE, SERG, TRIZ and VVK) present major azimuthal gaps to the north, as a result of lower seismic activity in their vicinity at the respective azimuthal range. For the southern stations, a more complex explanation is required. While events exist in regions where azimuthal gaps are observed in the SW part of the study area, their angles of incidence are in most cases greater than $45^{\circ}$, outside the shearwave window. As a result, ROD3 presents lack of events to the south. In addition, LAKA is almost dominated by results in the epicentral area of the seismic swarm, which is consistent with the temporal distribution of the analyzed events in this station (i.e. most results are concentrated during the period between May and November). Almost all stations present a narrow range of fast shear-

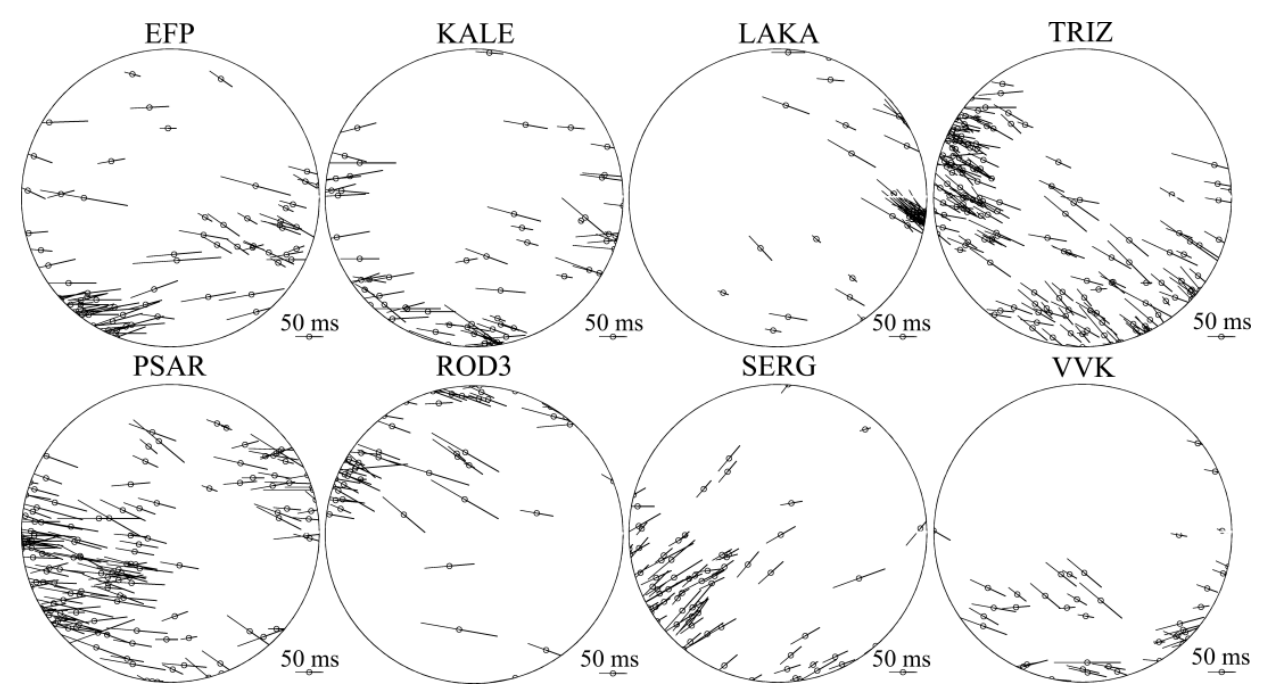

Figure 3 - Polar equal-area projections of the upper hemisphere for the $\mathbf{S}_{\text {fast }}$ polarization directions for each station. The length of the bars is proportional to the time delay of each event. 
wave polarization directions and, as a consequence, small respective mean error values. In all stations the majority of determined $S_{\text {fast }}$ polarization directions are within $\pm 30^{\circ}$ off the equivalent mean direction.

Overall, a set of 643 results was obtained by 535 events, in 8 stations (Fig. 4). All stations present mean polarization directions (Fig. 4) almost parallel to the regional topographic depression that characterizes the $\mathrm{GoC}$, consistent with its direction of extension, independent of each event's azimuth. Specifically, the northern stations, i.e. EFP, KALE, PSAR, TRIZ and VVK present mean directions equal to $\mathrm{N} 91^{\circ} \mathrm{E}, \mathrm{N} 99^{\circ} \mathrm{E}, \mathrm{N} 98^{\circ} \mathrm{E}, \mathrm{N} 118^{\circ} \mathrm{E}$ and $\mathrm{N} 101^{\circ} \mathrm{E}$, respectively, while in stations LAKA and ROD3, located near the south coast of the WGoC, the determined mean directions are equal to $\mathrm{N} 123^{\circ} \mathrm{E}$ and $\mathrm{N} 107^{\circ} \mathrm{E}$, respectively. One exception concerns SERG, located off the northern coast, where the corresponding mean direction is $\mathrm{N}^{\circ} 6^{\circ} \mathrm{E}$. A sum of the statistical parameters of the results per station is presented in Table 1. Mean directions of polarization and their corresponding errors have been calculated using circular statistics (Berens, 2009).

Table 1 - Summary of shear-wave splitting analysis' results per station. Mean errors are also provided.

\begin{tabular}{|c|c|c|c|c|}
\hline Station & $\begin{array}{c}\text { Mean Direction of } \\
\text { Polarization }\left(\mathrm{N}^{\circ} \mathrm{E}\right)\end{array}$ & $\begin{array}{c}\text { Mean Direction of } \\
\text { Polarization Error }\left({ }^{\circ}\right)\end{array}$ & $\begin{array}{c}\text { Mean Time } \\
\text { Delay }(\mathrm{ms})\end{array}$ & $\begin{array}{c}\text { Mean Time } \\
\text { Delay Error (ms) }\end{array}$ \\
\hline EFP & 91 & 5 & 84 & 4 \\
\hline KALE & 99 & 5 & 80 & 4 \\
\hline LAKA & 123 & 5 & 70 & 5 \\
\hline PSAR & 98 & 3 & 88 & 3 \\
\hline ROD3 & 107 & 4 & 83 & 5 \\
\hline SERG & 56 & 3 & 58 & 3 \\
\hline TRIZ & 118 & 3 & 61 & 2 \\
\hline VVK & 101 & 6 & 58 & 4 \\
\hline
\end{tabular}

Time delays can be an indicator of the magnitude of anisotropy and, thus, increased time delay values correspond to stronger anisotropy in the propagation medium and vice versa. Based on the mean time delay, the distinction of two groups is possible. Stations EFP, KALE, LAKA, PSAR and ROD3 present mean time delays between $70 \mathrm{~ms}$ and $90 \mathrm{~ms}(84 \mathrm{~ms}, 80 \mathrm{~ms}, 70 \mathrm{~ms}, 88 \mathrm{~ms}$ and $83 \mathrm{~ms}$, respectively) while stations SERG, TRIZ and VVK are characterized by values of approximately 60 $\mathrm{ms}(58 \mathrm{~ms}, 61 \mathrm{~ms}$ and $58 \mathrm{~ms}$, respectively). Nevertheless, the differences between the two groups are not significant (the maximum mean time delay has a difference of $30 \mathrm{~ms}$ from the minimum) and the spatial distribution does not provide any correlation with the observed mean time delays.

\section{Discussion}

During 2013, a period of extended significant unrest was observed in the broader area of the WGoC, featuring an intense seismic swarm located off the coast of Aigion between May and August (Chouliaras et al., 2015; Kapetanidis et al., 2015). The total annual seismicity presents a curved distribution from Rio - Antirion in the west to Antikyra in the east, roughly delineated by the epicentres in Fig. 4. In the mainland of Peloponnese, a scattered population of events is present with a general linear NW - SE distribution. The largest event in the area was the $\mathrm{M}_{\mathrm{w}}=3.9$ earthquake on 28 April 2013 04:49:56.78 (GMT). The focal depths of these events mainly range between $8 \mathrm{~km}$ and $10 \mathrm{~km}$. The provision of a multitude of earthquakes and the dense nature of the local seismological networks, namely HUSN and CRLN, were critical factors in the selection of this area for the study of local crustal anisotropy.

Events presenting an angle of incidence less than $45^{\circ}$ in at least one station, inside the shear-wave window, were initially selected. Additional distinction of suitable events occurred during the analysis, since it required visual inspection of each waveform. Rejection of events during this 
procedure is a result of vague shear-wave arrivals or elliptic polarization of the fast shear-wave due to noise. The final number of produced results is equal to 643 , for 8 stations, derived from 535 earthquakes.

The existence of an anisotropic layer beneath the WGoC is observed. The mean polarization direction of almost all stations (Fig. 4) is parallel to the regional faults' strike (Armijo et al., 1996; Rigo et al., 1996; Bell et al., 2009) and perpendicular to the extension of the neotectonic structure, as measured by GPS studies (Chousianitis et al., 2013). From the above, it is evident that the maximum horizontal compressive stress axis is trending at an approximately WNW - ESE direction. The previous observations can be explained by the EDA model, where the anisotropy direction is parallel to the strike of the rockmass' microcracks (Crampin, 1978). Nevertheless, deviations from the mean direction can be associated with migration of pore fluids, as mentioned in the APE model (Zatsepin and Crampin, 1997). Similar variations have been observed in the area of Villia, located in the eastern part of the GoC (Kaviris et al., 2014).

Previous studies in the area (Bouin et al., 1996; Bernard et al., 1997b; Kaviris et al., 2008, 2010; Giannopoulos et al., 2015) have produced results, concerning the mean anisotropy direction, similar to the ones in the current study. An important exception is the mean polarization direction in PSAR station by Bouin et al. (1996), where its value was found equal to $\mathrm{N} 70^{\circ} \mathrm{E}$ and $\mathrm{N} 60^{\circ} \mathrm{E}$, for 1991 and 1992, respectively, employing an automatic measurement procedure, while the current study obtained a measurement equal to $\mathrm{N} 98^{\circ} \mathrm{E}$, in agreement with the $\mathrm{N} 105^{\circ} \mathrm{E}$ direction found by Kaviris et al. (2008), who utilized the same visual inspection method as the current study. Results from station VVK are presented for the first time.

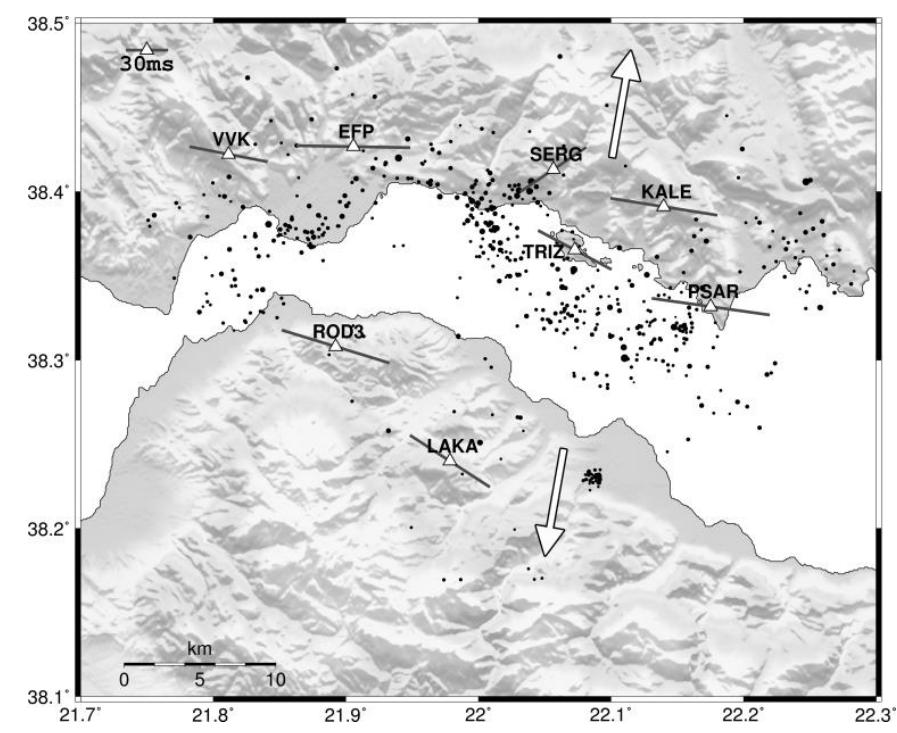

Figure 4 - Mean $S_{\text {fast }}$ polarization directions at 8 stations at the $\mathrm{WGoC}$. The arrows correspond to the direction of extension of the gulf. Epicentres of the 535 used events are also presented.

The above observations are evidence of no major variations in the direction of the fast shear-wave, and consequently the orientation of the microcracks, during the past decades. Notable deviations can be explained by the different measurement method of each research team. It is no coincidence that most differences can be found between results derived from automatic methods and non-automatic (as in the case of our study). Lesser deviations of results can be attributed to the APE model. As expected, no $90^{\circ}$-flips (Crampin et al., 2013) were observed in the temporal distribution of the polarization direction in any station, being a characteristic of volcanic settings under critical conditions (Bianco et al., 2006). 
Time delays present two main groups of stations, but these do not correlate with any suggestable spatial distribution of anisotropy. In comparison to older studies, our analysis provided varied differences. For instance, the mean time delay value measured in 2013 in the area of Psaromyta (PSAR station) is far higher, equal to $88 \mathrm{~ms}$, than the ones observed by Bouin et al. (1996), which were $38 \mathrm{~ms}$ for 1991 and $54 \mathrm{~ms}$ for 1992. The opposite is observed for LAKA station, where Kaviris et al. $(2008,2010)$ found time delay ranges $(24-104 \mathrm{~ms}$ and $10-130 \mathrm{~ms}$, respectively) similar to those derived by the current study.

While the direction of anisotropy is shown to be a somewhat stable feature of microcracks contained in the rockmass beneath the WGoC, the magnitude of anisotropy, represented by time delays, can be altered tremendously. Such variations have been observed in smaller periods of time (Crampin et al., 1999), than the ones presented in the comparison of results between the current study and previous one. Additional analysis of daily measurements of time delays can provide further insight to the processes of stress accumulation and relaxation. This can be achieved by utilizing normalized time delays, which will be the scope of further research on the presented data.

\section{Acknowledgements}

We would like to thank the scientists and personnel of the Geodynamic Institute of the National Observatory of Athens and of the Seismological Laboratory of the University of Patras who participated in the installation or maintenance of the permanent and temporary stations belonging to the HUSN network and the French research team of the CRL network. The present study was partially financed by the Special Account for Research Grants of the National and Kapodistrian University of Athens (UoA - S.A.R.G.).

\section{References}

Armijo, R., Meyer, B., King, G., Rigo, A. and Papanastassiou, D., 1996. Quaternary evolution of the Corinth Rift and its implications for the Late Cenozoic evolution of the Aegean, Geophys. J. Int., 126, 11-53.

Bell, R.E., McNeill, L.C., Bull, J.M., Henstock, T.J., Collier, R.E.L. and Leeder, M.R., 2009. Fault architecture, basin structure and evolution of the Gulf of Corinth rift, central Greece, Basin Res., 21(6), 824-855, doi: 10.1111/j.1365-2117.2009.00401.x.

Berens, P., 2009. CircStat: A MATLAB Toolbox for Circular Statistics, J. Stat. Softw., 31(10), 1-21.

Bernard, P. and Zollo, A., 1989. Inversion of near-source S polarization for parameters of doublecouple point sources, Bull. Seism. Soc. Am., 79(6), 1779-1809.

Bernard, P., Briole, P., Meyer, B., Gomez, J.-M., Tiberi, C., Berge, C., Cattin, R., Hatzfeld, D., Lachet, C., Lebrun, B., Deschamps. A., Courboulex, F., Larroque, C., Rigo, A., Massonnet, D., Papadimitriou P., Kassaras, J., Diagourtas, D., Makropoulos, K., Veis, G., Papazisi, E., Mitsakaki, C., Karakostas, V., Papadimitriou, E., Papanatassiou, D., Chouliaras, M. and Stavrakakis, G., 1997a. The Ms=6.2, June 15, 1995 Aigion earthquake (Greece): evidence for low-angle normal faulting in the Corinth rift, J. Seismol., 1, 131-150, doi: 10.1023/A:1009795618839.

Bernard, P., Chouliaras, G., Tzanis, A., Briole, P., Bouin, M., Tellez, J., Stavrakakis, G. and Makropoulos, K., 1997b. Seismic and electrical anisotropy in the Mornos delta, Gulf of Corinth, Greece and its relationship with GPS strain measurements, Geophys. Res. Lett., 24(17), 2227-2230.

Bianco, F., Scarfi, L., Del Pezzo, E. and Patanè, D., 2006. Shear wave splitting changes associated with the 2001 volcanic eruption on Mt Etna, Geophys. J. Int., 167(2), 959-967.

Booth, D.C. and Crampin, S., 1985. Shear-wave polarizations on a curved wavefront at an isotropic free surface, Geophys. J. R. Astr. Soc., 83, 31-45. 
Bouin, M., Téllez, J. and Bernard, P., 1996. Seismic anisotropy around the Gulf of Corinth, Greece, deduced from three-component seismograms of local earthquakes and its relationship with crustal strain, J. Geophys. Res., 101(B3), 5797-5811.

Chouliaras, G., Kassaras, I., Kapetanidis, V., Petrou, P. and Drakatos, G., 2015. Seismotectonic analysis of the 2013 seismic sequence at the western Corinth Rift, J. Geodyn., 90, 42-57.

Chousianitis, K., Ganas, A. and Gianniou, M., 2013. Kinematic interpretation of present-day crustal deformation in central Greece from continuous GPS measurements, J. Geodyn., 71, 1-13.

Crampin, S., 1978. Seismic-wave propagation through a cracked solid: polarization as a possible dilatancy diagnostic, Geophys. J. Int., 53(3), 467-496, doi: 10.1111/j.1365246X.1978.tb03754.x.

Crampin, S. and Zatsepin, S.V., 1997. Changes of Strain before Earthquakes: The Possibility of Routine Monitoring of Both Long-Term and Short-Term Precursors, J. Phys. Earth, 45(1), 41-66.

Crampin, S., Chesnokov, E.M. and Hipkin, R.G., 1984. Seismic anisotropy - the state of the art: II. Geophys. J. R. Astr. Soc., 76, 1-16, doi: 10.1111/j.1365-246X.1984.tb05017.x.

Crampin, S., Volti, T. and Stefánsson, R., 1999. A successfully stress-forecast earthquake, Geophys. J. Int., 138, F1-F5.

Crampin, S., Gao, Y. and De Santis, A., 2013. A few earthquake conundrums resolved, J. Asian Earth Sci., 62, 501-509, doi: 10.1016/j.jseaes.2012.10.036.

Duverger, C., Godano, M., Bernard, P., Lyon-Caen, H. and Lambotte, S., 2015. The 2003-2004 seismic swarm in the western Corinth rift: Evidence for a multiscale pore pressure diffusion process along a permeable fault system, Geophys. Res. Lett., doi: 10.1002/2015GL065298.

Galanopoulos, A., 1936. Seismicity of Achaia and the adjacent areas of Mesolongi and Nafpaktos, Ph.D Thesis, Athens, University of Athens, 23 pp. (in Greek).

Galanopoulos, A., 1960. A catalogue of shocks in Greece with I $>$ VI or M $\geq 5$ for the years 1801 to 1958, Athens, Seismological Laboratory, University of Athens.

Giannopoulos, D., Sokos, E., Konstantinou, K.I. and Tselentis, G.-A., 2015. Shear wave splitting and VP/VS variations before and after the Efpalio earthquake sequence, western Gulf of Corinth, Greece, Geophys. J. Int., 200, 1436-1448, doi: 10.1093/gji/ggu467.

Ganas, A., Chousianitis, K., Batsi, E., Kolligri, M., Agalos, A., Chouliaras, G. and Makropoulos, K., 2013. The January 2010 Efpalio earthquakes (Gulf of Corinth, Central Greece): earthquake interactions and blind normal faulting, J. Seismol., 17, 465-484, doi: 10.1007/s10950-012-9331-6.

Hatzfeld, D., Kementzetzidou, D., Karakostas, V., Ziazia, M., Nothard, S., Diagourtas, D., Deschamps, A., Karakaisis, G., Papadimitriou, P., Scordilis, M., Smith, R., Voulgaris, N., Kiratzi, S., Makropoulos, K., Bouin, M.P. and Bernard, P., 1996. The Galaxidi earthquake of 18 November 1992: A possible asperity within the normal fault system of the Gulf of Corinth (Greece), Bull. Seism. Soc. Am., 86(6), 1987-1991.

Hatzfeld, D., Karakostas, V., Ziazia, M., Kassaras, I., Papadimitriou, E., Makropoulos, K., Voulgaris, N. and Papaioannou, C., 2000. Microseismicity and faulting geometry in the Gulf of Corinth (Greece), Geophys. J. Int., 141(2), 438-456. doi: 10.1046/j.1365246x.2000.00092.x.

Kapetanidis, V. and Papadimitriou, P., 2011. Estimation of arrival-times in intense seismic sequences using a Master-Events methodology based on waveform similarity, Geophys. J. Int., 187, 889-917.

Kapetanidis, V., Deschamps, A., Papadimitriou, P., Matrullo, E., Karakonstantis, A., Bozionelos, G., Kaviris, G., Serpetsidaki, A., Lyon-Caen, H., Voulgaris, N., Bernard, P., Sokos, E. and Makropoulos, K., 2015. The 2013 earthquake swarm in Helike, Greece: seismic activity at the root of old normal faults, Geophys. J. Int., 202, 2044-2073, doi: 10.1093/gji/ggv249.

Karakonstantis, A. and Papadimitriou, P., 2010. Earthquake relocation in Greece using a unified and homogenized seismological catalogue, Bull. Geol. Soc. Greece, Proc. of the 12th International Congress, Patras, May 2010, XLIII/4, 2043-2052. 
Kaviris, G., 2003. Study of Seismic Source Properties in of the Eastern Gulf of Corinth, Ph.D Thesis, Athens, Geophysics-Geothermics Department, Faculty of Geology, University of Athens, 400 pp. (in Greek).

Kaviris, G., Papadimitriou, P. and Makropoulos, K., 2008. An Overview of Anisotropy Studies in Central Greece using recordings around the Gulf of Corinth (Greece) and aftershocks of the 1999 Athens Earthquake, Short Papers, $31^{\text {st }}$ ESC General Assembly, Hersonissos, Crete, Greece, 215-223.

Kaviris, G., Papadimitriou, P. and Makropoulos, K., 2010. Anisotropy Study of the February 4Th 2008 Swarm in Nw Peloponnesus (Greece ), Bull. Geol. Soc. Greece, XLIII/4, 2084-2092.

Kaviris, G., Papadimitriou, P., Kravvariti, Ph., Kapetanidis, V., Karakonstantis, A., Voulgaris, N., and Makropoulos, K., 2015. A detailed seismic anisotropy study during the 2011-2012 unrest period in the Santorini Volcanic Complex, Phys. Earth. Plan. Inter., 238, 51-88.

Kaviris, G., Kapetanidis, V., Kravvariti, P., Karakonstantis, A., Bozionelos, G., Papadimitriou, P. and Makropoulos, K., 2014. Anisotropy Study in Villia (E. Corinth Gulf, Greece), Full Paper, 2nd European Conference on Earthquake Engineering and Seismology, Istanbul, Turkey.

Kouskouna, V. and Makropoulos, K., 2004. Historical earthquake investigations in Greece, Ann. Geophys.-Italy., 42(2/3), 723-731.

Liu, Y., Zhang, H., Thurber, C. and Roecker, S., 2008. Shear wave anisotropy in the crust around the San Andreas fault near Parkfield: Spatial and temporal analysis, Geophys. J. Int., 172(3), 957-970.

Lyon-Caen, H., Papadimitriou, P., Deschamps, A., Bernard, P., Makropoulos, K., Pacchiani, F. and Patau, G., 2004. First results of the CRLN seismic network in the western Corinth Rift: evidence for old-fault reactivation, C.R. Geoscience, 336, 343-351, doi: 10.1016/j.crte.2003.12.004.

Makropoulos, K.C. and Burton, P.W., 1984. Greek Tectonics and Seismicity, Tectonophysics, 106, 275-304.

Makropoulos, K., Kaviris, G. and Kouskouna, V., 2012. An updated and extended earthquake catalogue for Greece and adjacent areas since 1900, Nat. Hazards Earth. Syst. Sci., 12, 14251430 .

Papadimitriou, P., Kaviris, G. and Makropoulos, K., 1999. Evidence of shear-wave splitting in the eastern Corinthian Gulf (Greece), Phys, Earth Plan. Inter., 114(1-2), 3-13.

Papadimitriou, P., Kaviris, G., Karakonstantis, A. and Makropoulos, K., 2010. The Cornet seismological network: 10 years of operation, recorded seismicity and significant applications, Annal. Geol. Des Pays Hell., 45, 193-208.

Papadimitriou, P., Kapetanidis, V., Karakonstantis, A., Kaviris, G., Voulgaris, N. and Makropoulos, K., 2015. The Santorini Volcanic Complex: A detailed multi-parameter seismological approach with emphasis on the 2011-2012 unrest period, J. Geodyn., 85, 32-57, doi: 10.1016/j.jog.2014.12.004.

Papazachos, V. and Papazachou, K., 2003. The Earthquakes of Greece, Thessaloniki, Ziti Publications, 286 pp. (in Greek).

Rigo, A., Lyon-Caen, H., Armijo, R., Deschamps, A., Hatzfeld, D., Makropoulos, K., Papadimitriou, P. and Kassaras, I., 1996. A microseismic study in the western part of the Gulf of Corinth (Greece): implications for large-scale normal faulting mechanisms, Geophys. J. Int., 126(3), 663-688.

Valcke, S.L.A., Casey, M., Lloyd, G.E., Kendall, J.-M. and Fisher, Q.J., 2006. Lattice preferred orientation and seismic anisotropy in sedimentary rocks, Geophys. J. Int., 166(2), 652-666.

Zatsepin, S. and Crampin, S., 1997. Modelling the compliance of crustal rock-I. Response of shearwave splitting to differential stress, Geophys. J. Int., 129, 477-494, doi: 10.1111/j.1365246X.1997.tb04488.x. 